\title{
The Effect of Using Look, Spell and Read (LSR) Interactive Application towards Reading (CV+CVC) Skills among Slow Learner Students
}

\author{
Nurulhusna Rashid, Nurulwahida Azid* \\ School of Education and Modern Languages, Universiti Utara Malaysia, Malaysia
}

Received August 25, 2020; Revised November 12, 2020; Accepted November 29, 2020

\section{Cite This Paper in the following Citation Styles}

(a): [1] Nurulhusna Rashid, Nurulwahida Azid, "The Effect of Using Look, Spell and Read (LSR) Interactive Application towards Reading $(C V+C V C)$ Skills among Slow Learner Students," Universal Journal of Educational Research, Vol. 8, No. 12A, pp. 7905-7914, 2020. DOI: 10.13189/ujer.2020.082579.

(b): Nurulhusna Rashid, Nurulwahida Azid (2020). The Effect of Using Look, Spell and Read (LSR) Interactive Application towards Reading $(C V+C V C)$ Skills among Slow Learner Students. Universal Journal of Educational Research, 8(12A), 7905-7914. DOI: 10.13189/ujer.2020.082579.

Copyright $\bigcirc 2020$ by authors, all rights reserved. Authors agree that this article remains permanently open access under the terms of the Creative Commons Attribution License 4.0 International License

\begin{abstract}
Language literacy is the most important skill to be mastered because it is one of the mediums used to deliver teaching contents in the classroom. One of the language literacy needed in learning is the reading skills. This research aimed to identify the impact of using LSR interactive tool on slow learner students' reading skills. A total of thirty slow learner students and two teachers who had five years of experience in teaching special education class were selected as respondents. This research was pre experimental in design because it involved only one group of study sample. The instruments used were pre-test and post-test, and interview protocols for teachers and pupils. Data were analyzed using descriptive and inferential analysis through Statistical Program Social Science (SPSS) version 22. The paired t-test result showed that there were positive and significant impacts $(\mathrm{t}=-23.57, \mathrm{df}=29, \mathrm{P}<0.05)$ of using LSR interactive tool on slow learner students' reading skills. Meanwhile qualitative data through teacher and student interviews showed similarity when both groups agreed that using LSR interactive tool helps slow learner students improve their reading skills. The use of multimedia elements such as text, graphics, animation, video and audio has helped a lot in capturing students' attention and interest and this also has indirectly helped improve their reading ability. All students suggested that more words be built in LSR and the use of 3D graphics be increased as these have attracted them to learn. It is hoped that this study can be a trigger and reference for further
\end{abstract}

studies related to the use of interactive applications in particular to assist the learning process of special education students.

Keywords Interactive Application, Pre-experimental Design, Slow Learner Students, Special Education, Consonant-Vocal-Consonant (CVC)

\section{Introduction}

The world has grown rapidly in many ways. Various policies and laws have been renewed so that all parties are treated fairly. For example, the No Child Left Behind Act (NCLB) was introduced in 2001 to replace the Elementary and Secondary Education Act 1965. The Act was introduced to focus on the American education system in particular that is no longer competitive internationally. As such, the government has taken a leading role in giving all groups of students the access to equal rights in education such as special education students, poor and marginalized students, moderate-performing students and second language learners [1]. This also happens in educational development in Malaysia. Equality in the education system is important to ensure students' academic achievement. According to the Malaysian Education Development Plan 2013-2025, the current education 
system is expected to provide exciting learning outcomes. The Ministry of Education will also continue to improve the education system in line with the National Transformation 2050 (TN50) by 2050. This is no exception for students in special education classes. The School of Special Education as well as the Integrated Special Education Program has implemented national curricula as well as alternative curricula as a means of delivering quality education to students with learning disabilities. For primary school students, they use the Primary School Curriculum which emphasizes special education based education. National Curriculum for Primary Special Education (KSSR PK) Curriculum of Learning Disabilities are built in accordance with the National Philosophy of Education based on principles of integrated approach, holistic individual development, equal opportunity for all students and lifelong education. To meet the individual needs, teaching and learning Special Education of Learning Disabilities are formulated in accordance with the rules of education [2]. This curriculum has been prepared by the Ministry of Education Malaysia. These special education students have the same educational needs as mainstream students, but they need to be stimulated using a slightly different and more focused method.

This study emphasized on reading Consonant-Vocal + Consonant-Vocal-Consonant $(\mathrm{CV}+\mathrm{CVC})$ word that appeared in the Malay Language curriculum of Special Education. Malay Language curriculum was introduced with the aim to equip students with language and communication abilities to meet the needs of themselves, learning, interaction and communication with surrounding communities without any restrictions. This means that speaking and language skills can provide children with the opportunity to build social interactions, gather knowledge, build a positive self-concept and guide acquisition of reading skills [3]. The goals set in this curriculum are designed to help students in communication, humanities and the environment to identify the abilities and potentials of each student. Pronunciation and language skills are central to all areas of children's development and rely on many aspects of social, cognitive and emotional behavior [4]. As a catalyst for this curriculum, teachers need to be smart and creative in creating learning environments that will interest students and provide activities that are in line with students' ability to actively engage. The variety of teaching techniques and methods can also make the learning sessions interesting and make the students interested in the subject. According to the study by [26], students with special needs need a teaching method that is modified according to the suitability of their cognitive level. Therefore, they can achieve positive changes in reading and writing skills. In addition, with a variety of teaching materials, teachers, other than improve students' reading and writing skills, can also improve the cognitive and socio-emotional skills of students with special needs.
In a study conducted by [5] entitled 'Principles and Implementation of Reading Activities in Primary School English Class, English Language Teaching', it is said that reading activities in the classroom need to be well designed to guide students' reading skills. Good reading skills can benefit students in their learning process in the future and can foster students' interests in reading. Students with disabilities like slow learners can misunderstand the text, not read well nor share ideas [6]. The study findings by [28] stated that slow learner students have speech disorders as in articulation problems; other problems such as reading, sentence construction and understanding grammatical rules. They desperately need speech stimulation through the process of learning while playing and communicating with older people. Their language skills become limited due to several factors such as poor speech and language background, limited experience, and emotional as well as social factors as a result of their weak thinking abilities. These slow learner students can improve their reading skills and language skills with the help and guidance of their primary teacher in terms of stimulating their existing knowledge.

Further, [7] in his study stated that the enjoyment of reading in the classroom of learning disabilities will increase if there are guidance and teaching aids that meet the needs of students. Teachers act as a mediator to show that reading is an exciting and enjoyable learning activity. This study also showed that students with learning disabilities need appropriate support in developing meaningful reading skills. The study also highlighted the use of interactive teaching aids such as the audio visual mediums to help in the learning process of slow learners. Audio-visual media is not only audible but is also accessible to students. Indirectly it helps students to learn more and can help students to build their self-esteem. [8] stated that images in audio-visual devices must attract students' attention. The tools should be colorful, centered and designed to enhance students' inspiration. In addition, there are studies related to the use of teaching aids for special needs students. [9] suggested a combination of audio-visual in learning. The aim of this study was to create a fun learning concept among students with learning disabilities. The findings of the study found that there was a significant increase in the learning of children with learning disabilities as well as preschool children. The use of audio-visual teaching tools can benefit students in terms of visual learning, real-life learning as well as reactive and proactive mechanisms rather than reading static contents from books. Furthermore, [10] in his study stated that audio-visual learning processes can improve students' feedback on their learning. In addition, the audio-visual learning process enhances social interaction among students and improves their intellectual ability. $\mathrm{He}$ also argued that students with learning difficulties could improve their reading skills and actively learn if teachers use appropriate teaching strategies and effective teaching 
aids during the teaching and learning sessions.

\subsection{Problem Statements}

Nowadays, teaching methods that teachers adapt to use in the classroom are important in ensuring that the students receive the best teaching content. Various efforts from various levels such as teachers, education departments and ministries have shown continuous efforts in helping to improve student performance in various fields, especially reading skills among students. One of the efforts of the ministry is to participate in educational activities such as participating in the International Program for International Student Assessment (PISA) in three areas: Literacy, Mathematics and Science. PISA is conducted by the Organization for Economic Co-operation and Development (OECD) or Economic Cooperation and Development Organization. The organization collaborates with governments from all countries involved in conducting research in various fields including education [12].

Based on Table 1, reading literacy results of the PISA assessment in 2012 showed a significant decline to the 59 th place out of 64 countries involved. This result contrasted with the achievement of the PISA reading literacy assessment in 2009, which ranked 55th out of 75 countries involved. According to the report on achievement of PISA assessment for language literacy in 2012, Malaysian students were in the lower reading of 1B (second level in lower reading proficiency) at $16.4 \%$ while only $30.3 \%$ were in level $1 \mathrm{~A}$ (first level in lower reading proficiency). As a result, $52.5 \%$ of students failed to meet the minimum literacy level. This achievement percentage was still below the OECD average of $16.5 \%$. PISA's performance for 2015 showed a 431 increase in language literacy scores compared to 2012, with a total score of 398. However, Malaysia's position on PISA's 2015 assessment declined to $49^{\text {th }}$ place from 72 countries involved [12](Ministry of Education Malaysia, 2013). According to the Annual Report of the [12] Malaysian Education Development Plan (2016), the improvement in performance in the PISA assessment was due to the application of higher order thinking skills (HOTS) across the field. In conclusion, the literacy level of students in Malaysia is still poor and requires the attention of all educators to work together to improve their literacy skills.

Table 1. PISA Reading Literacy Achievements for 2009 and 2012

\begin{tabular}{ccc}
\hline \multirow{2}{*}{ Year } & \multicolumn{2}{c}{ Reading Literacy } \\
\cline { 2 - 3 } & Score & Rank \\
\hline $\mathbf{2 0 0 9}$ & 414 & $55 / 74$ \\
\hline $\mathbf{2 0 1 2}$ & 398 & $59 / 65$ \\
\hline $\mathbf{2 0 1 5}$ & 431 & $49 / 72$ \\
\hline
\end{tabular}

Source: [12].

\subsection{Research Questions}

This study was conducted to answer the following research questions:

a). What is the proficiency profile of students' achievement before and after treatment in terms of $\mathrm{CV}+\mathrm{CVC}$ reading skills through pre-test and post-test?

b). Are there significant effects in teaching and learning assisted by LSR interactive application in the post-test?

c). How do teachers view teaching and learning using LSR interactive application?

d). How do pupils view teaching and learning using LSR interactive application?

\subsection{Hypothesis}

H01: There is no significant effect in teaching and learning assisted by LSR interactive application in the post-test.

\section{Multimedia Learning Model}

This study emphasized the use of innovative teaching aids in helping teachers carry out the teaching and learning process. As such, the cognitive learning model, Mayer and Moreno's Multimedia Learning Model (2003) will be adapted. This interactive application of LSR was developed based on the [11] Multimedia Learning Model to aid in the teaching and learning process of reading $\mathrm{CV}$ $+\mathrm{CVC}$ words among slow learner students.

This model explains that the brain receives information and processes of information in two different channels based on how the information is presented. There are two channels: audio and visual. Audio channel includes words used in narratives and non-verbal sounds. While visual channel includes pictures, videos, charts and printed words. These two channels are processed separately. This model states that learning is an active process involving the selection, filtering, organization and integration of information based on existing knowledge. The innovative teaching aids created contained every element found in this multimedia learning model which aims to enhance understanding and skills through an effective learning process. An effective learning process means that students master the content of their learning, the construction of new knowledge and the skills of students' combined existing knowledge with the acquisition of learning content to form new knowledge [11].

Figure 1 shows the relationship between cognitive processes and the multimedia elements involved in the process of building new information and knowledge. This model of learning involves three assumptions based on the use of multimedia in the teaching and learning process. 


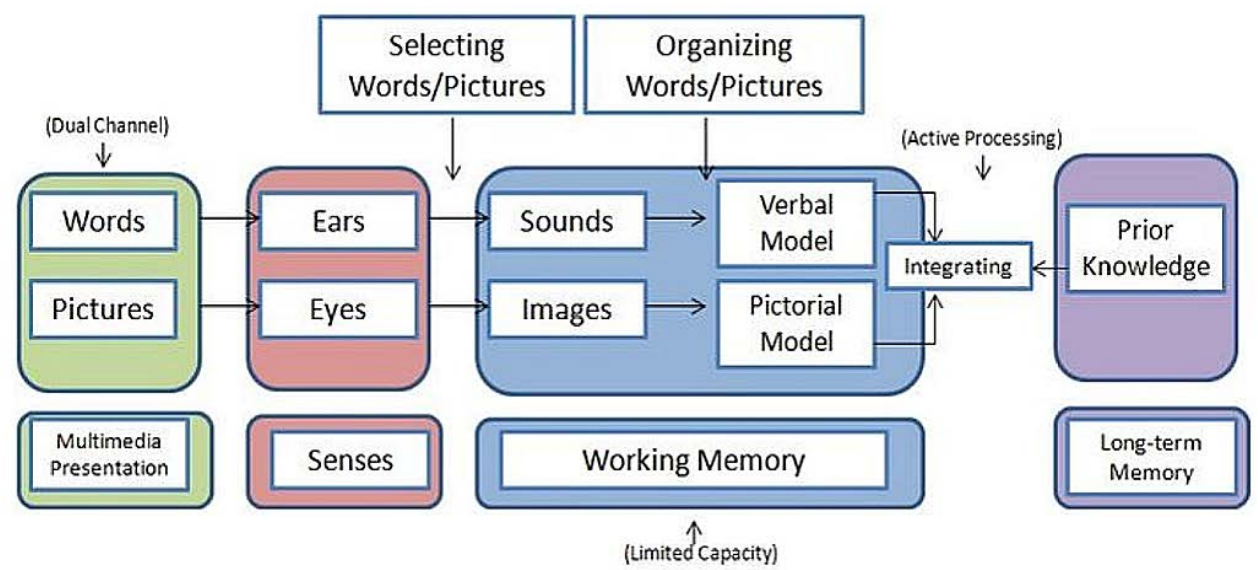

Figure 1. The Cognitive Theory of Multimedia Learning [11].

\section{LSR Interactive Application Creation based on Mayer and Moreno's Multimedia Learning Model (2003)}

This LSR interactive application was built by researchers to help slow learners in special education classes. This interactive application focuses on CV + CVC syllabus reading skills. This application contained three learning activities namely, Let's Read, Quiz 1 and Quiz 2. Mayer's multimedia learning model was used in the construction of this application. The ability to recognize syllable sounds and pronounce syllables to form the main words was emphasized in the first phase of the learning activity, which was the pronouncing activity. This learning activity involved the presentation of multimedia audio and visuals such as the use of pictures, words, music background, sounds background and multi-colored interface that stimulate the visual and hearing senses [21]. Students then processed all these sensory inputs into a short term working memory. The integration of technology as a medium in teaching and learning also can stimulate students thinking skills [22].

On each interface there was a visual and an audio element that introduced the animal picture and for students to pronounce the CV + CVC syllables and words correctly. This helped students to recognize the animals from the pictures, hear and pronounce the CV + CVC syllables and words correctly. This reading activity was in line with [11] multimedia learning model, which emphasizes the acquisition of audio and visual inputs to help build new knowledge through students' existing experiences or knowledge. In Quiz 1 assessment, students were tested on their knowledge of whether or not they know the CV + CVC syllables. The questions were in a combination of $\mathrm{CV}+\mathrm{CVC}$ syllables. Students were to choose a syllable that could be combined into the correct $\mathrm{CV}+\mathrm{CVC}$ words. This activity indirectly assessed students' short-term memory of the first phase of learning that was the Let's Read section. Quiz 2 was an assessment that evaluated students' long-term memory. This quiz required students to choose the correct $\mathrm{CV}+\mathrm{CVC}$ word according to the picture shown. This quiz provided appropriate audio reinforcement for students' answers. For any correct answer, 'congratulations' sound would be heard and 'try again' for incorrect answers. In line with Mayer's and Moreno's multimedia learning model, active processes involving multiple sensory sensations would help stimulate long-term memory and thus generate new knowledge. Therefore, the various senses in this app could help students master reading skills by building new knowledge through their learning experiences. The following is a screenshot of the LSR interactive application following a series of teaching and learning activities.



Figure 2. Introduction Display (Part 1) 


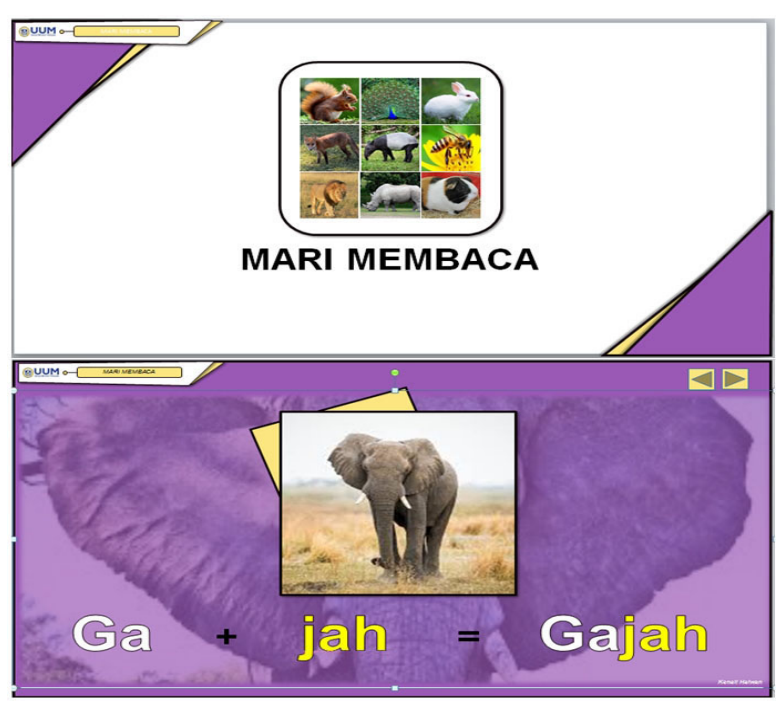

Figure 3. Let's Read (Part 2)

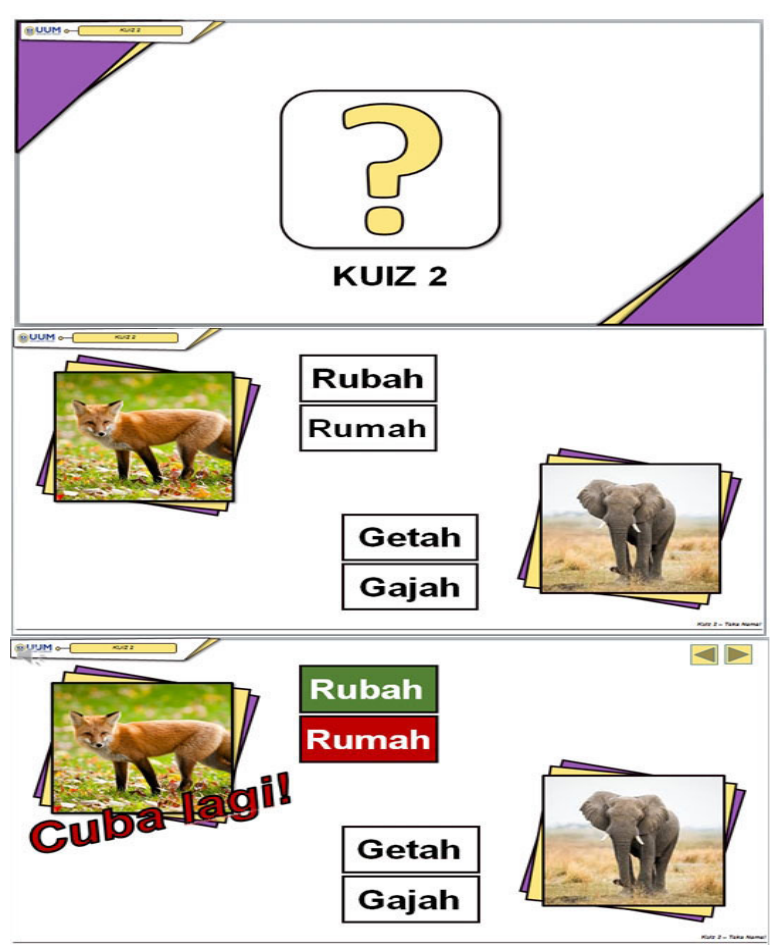

Figure 4. Example of quiz 1 (Part 3)

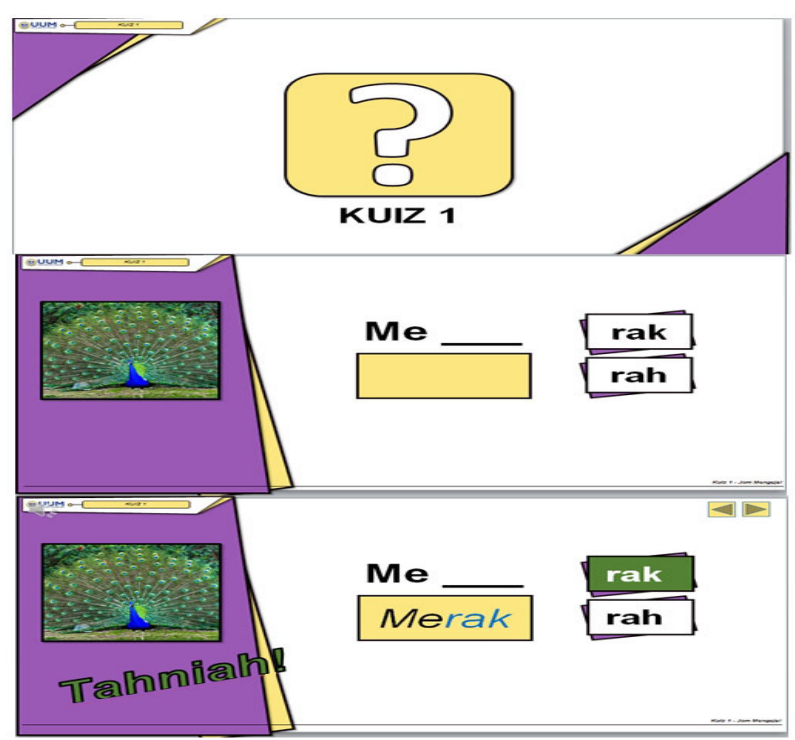

Figure 5. Example of quiz 2 (Part 4)

\section{Materials and Methods}

\subsection{Research Design}

The researcher has chosen the pre-experimental design using pre-test and post-test. Pre-test was conducted before students used the LSR interactive application while the post-test was conducted after teaching using LSR interactive application. The effectiveness of this application was assessed using a quantitative method such as analyzing pre and post test scores data as well as statistical inference checklists. The design of the pre-experimental study is one of the weakest study designs [13], however the rationale of using pre experimental in this study was because of the limited sample (just one special education class was available in each school). We believe pre-experimental research design is appropriate to execute this study as suggested by [13] in their study. Hence, the researcher has also included a qualitative method to obtain more information that was through interview sessions. The interview data was analyzed through content analysis. In this study, the pre-experimental study design used a small group of students who were trained using the LSR interactive application to help them master $\mathrm{CV}+\mathrm{CVC}$ word reading skills. No control group and comparison group were involved in this study. 


\subsection{Population and Sample}

This study used a non-random sampling technique. The researcher selected this sampling technique because the researcher has identified the specific characteristics of the selected sample based on the focus of this study [14]. 30 slow learner students who attended the special education class were the sample for this study. These students were identified based on health reports from student records and placement letters to the school. They have flexible access to education based on their level of cognitive ability and development. In addition, two teachers with experience in teaching slow learner students in special education classes for more than 5 years were also selected as study participants. Selecting a suitable study sample enables the researcher to obtain accurate research information or data [15]. Meanwhile, a total of 10 students were randomly selected to be interviewed.

\subsection{Instruments}

For this study, interview protocol, observation checklist as well as pre and post tests result were used. The instruments used in this study were divided into two; for quantitative data, the pre and post test results were used. Meanwhile, for qualitative data the researcher used interview protocols for teachers and 10 pupils. Interviews were conducted with two teachers who taught Bahasa Malaysia subject for slow learners in special education class with learning disabilities and have more than five years of teaching experience. This interview protocol contained four sections. The first section was to develop a positive relationship with the respondents. The second section was related to the respondents' background such as academic history, teaching experience and subjects taught. The third section covered the questions and issues of the study. Finally, the interviews were conducted to allow the respondents to submit additional suggestions regarding the use of LSR interactive application.

The pre- and post-test conducted in this study were to see the effectiveness of using LSR interactive application in helping slow learners in special education class to improve their $\mathrm{CV}+\mathrm{CVC}$ reading skills. This pre-test and post-test consisted of 20 multiple-choice objective questions. There were two sections in the pre and post tests; Section A contained 10 items and Section B also contained 10 items. The time allotted for test execution was 1 hour. The total score for each correct answer was 5 marks. The score was calculated as a percentage with an overall score of $100 \%$. The level of questions in pre- and post-test was based on Bloom's Taxonomy [16] at the level of remembering and understanding. The level of remembering was where students remember past lessons, terms, basic concepts and answers. This level required students to select, match, spell and tell, while the level of understanding involved students understanding the facts, organizing, comparing, explaining and proposing ideas.

\subsection{Statistics and Data Analysis}

Statistical analysis was also used for pre-and post test score analysis. Paired t-test is used to obtain pre-test and post-test difference scores [17]. This post-test determines whether the null hypothesis of the study is accepted or rejected. In this study, the result of paired t-test was explained using the statistical inference method. Paired t-test is used to find the comparative quantitative variable on the same individual for example looking at the effects before or after an intervention [18].

\subsection{Content Analysis}

This study used content analysis to analyze interview data. After obtaining information based on the interviews conducted, the researcher transcribed the interview data to examine the data more clearly. [19] argued that content analysis is one of the techniques of data summary. It is a technique that can compress a lot of text into smaller categories of content based on clear codes. Content analysis is done to extract data in a more meaningful way according to the identified themes [20]. In this study, the findings from the interview results were organized based on the contents obtained.

\section{Research Findings}

\subsection{Research Design}

The following is a graph of student achievement profiles for pre and post-test:

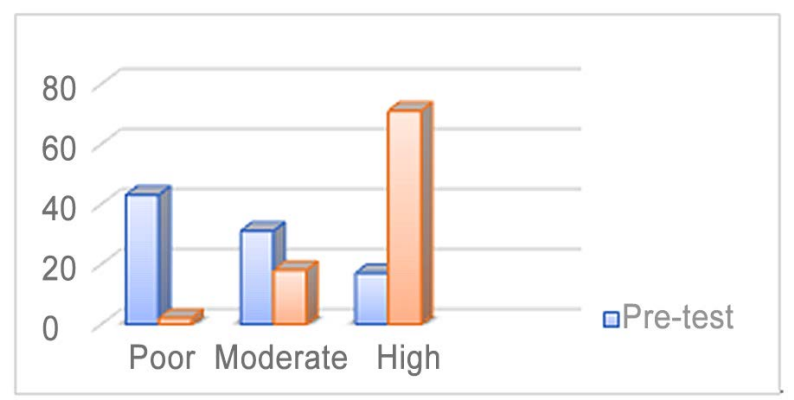

Figure 6. Student's Achievement Profile for Pre-Test and Post-Test

Based on Table 2, students' achievement in pre-test was less satisfactory. There were many students who were at the weak level and only a few students were at the high level. In contrast to the post-test, students' achievement was seen as satisfactory. Many students achieved a high level of achievement (in grades A and B). Therefore, it can be concluded that the use of LSR interactive tool could help in the development of $\mathrm{CV}+\mathrm{CVC}$ reading skill among slow learner students. 
Table 2. Result of Paired T-Test for Pre and Post Test

\begin{tabular}{lcccccccc}
\hline \multicolumn{10}{c}{ Paired Differences } \\
\hline \multicolumn{10}{c}{$\begin{array}{c}95 \% \text { Confidence Interval of the } \\
\text { Difference }\end{array}$} \\
\hline Mean & Std. Dev & $\begin{array}{c}\text { Std. Error } \\
\text { Mean }\end{array}$ & Lower & Upper & t & df & Sig. (2-tailed) \\
\hline $\begin{array}{l}\text { Pre-test scores }- \\
\text { Post-test scores }\end{array}$ & -36.83 & 8.59 & 1.563 & -40.03 & -33.64 & -23.57 & 29 & .000 \\
\hline
\end{tabular}

\subsection{Paired Sample T-Test Result}

Paired t-test was used to determine if the mean score for the post-test was higher than the pre-test mean score after the teacher had taught using the LSR interactive application. The following is a table of paired t-test result for pre and post-tests.

Based on Table 2, it can be seen that the result of the paired sample $t$-test was significant $(t=-23.57, \mathrm{df}=29, \mathrm{P}$ $<0.05)$. This result successfully rejected the null hypothesis for this study. Therefore, it was proven that the use of LSR interactive application could assist in the development of $\mathrm{CV}+\mathrm{CVC}$ reading skill among students. A high mean score after teaching using the LSR interactive application indicated that learning based on audio and visual media could improve reading skill score among slow learner students.

\subsection{Interview Findings}

To support the quantitative data, qualitative data through the implementation of interviews were obtained. The following are the results of the interview conducted with 2 teachers, and 10 students randomly selected from a total of 30 students.

Theme 1: LSR interactive application contained animations, images, colors and audio which could engage students in learning.

Teachers $(\mathrm{T})$ and pupils $(\mathrm{P})$ reacted positively to the relevance of the LSR interactive application in helping slow learners' learning. The use of this application has smoothly facilitated the teaching and learning process. Pupils also enjoyed using LSR interactive application as it contained animations, images, colors and audio. This indirectly helped students focus more on the learning process. Findings from pupil interviews found that they preferred SLR applications over textbooks due to the use of attractive graphics and animations that made it easier for them to understand the content of the lesson more easily.

Teachers' responses $(\mathrm{T})$

"In my view, the use of LSR interactive application is very relevant in assisting slow learners' learning. Because, all this while teaching these slow learners, I realize they love animations, music and colorful images. This can help them focus. When I used only textbooks or activity books, the pupils would always get bored and the class was difficult to control." (T1)

"I love seeing the pupils enjoy using this application in their learning. The application has syllable sounds, pictures, interesting images and pupils could also follow the correct word sounds. I see the pupils having fun too, and I was happy." (T2)

Pupils' responses (P)

"LSR had many colors, beautiful, there was a sound when I clicked on the button". (P1)

"It was fun to use this SLR interactive application, teacher. I like it because the pictures were moving (animation). Even more fun when I managed to answer correctly, the sound of applause would be heard causing me to be motivated to continue learning. Interface SLR interactive application was very colorful, attracted to me to learn". (P4)

"Ermmmm.... using this application was more fun and easy to understand than when teacher teaching used a book. I like to use this application because there were interesting sounds and animations, the pictures in this application looked alive and made me excited because of the use of attractive colors compared to the textbooks that teacher always uses while in class. Furthermore, if I use books, I easily feel bored while learning”. (P6)

"I like to use this LSR application, teacher. It was easy to use because the graphics were clear; the colors were attractive and beautiful. There were sounds that attracted me when learning. I like LSR better than textbook which only has pictures but no animation like LSR”. (P7)

"I really like this application, teacher. It feels like playing a game because there are moving pictures (animations) coupled with sounds that catch my attention. I'm happy teacher. Later, please develop another application like this yeah?”. (P10)

Theme 2: Reinforcement elements such as quizzes and repetitions found in LSR interactive application helped slow learners' in reading $\mathrm{CV}+\mathrm{CVC}$ words.

Teachers and pupils responded well to LSR interactive application in helping slow learners to read the $\mathrm{CV}+$ CVC words. In their views, the use of this application 
helped facilitate the teaching and learning process. In addition, this app could assess slow learners' reading of $\mathrm{CV}+\mathrm{CVC}$ words through Quiz 1 and Quiz 2 available in the LSR interactive application. Learning through the LSR interactive application allowed pupils to focus during the learning session. The response from the SLR allowed pupils to know automatically whether the position they were giving was right or wrong. Pupils were easier to learn with LSR than using textbooks.

Teachers' responses (T)

"This app was easy to use. I saw pupils enjoying it and they became focused. The sounds of the words were clear. Pupils followed it easily. Teachers could repeat parts which found to be confused by the pupils. Then, parts of Quizzes 1 and 2 could be understood by pupils. There was also the element of reinforcement. Therefore, it is possible that this interactive application could help as many slow learners as possible in their reading skills." (T1)

"Ermmm.. To me, this application could really help. Because this application has many recurring elements. If a pupil doesn't understand, I can click again to repeat the part they don't understand. Part 1 was interesting, too, with pictures, syllables, words and even background sounds and words. Pupils really like these things. They will not get bored to learn." (T2)

Pupils' responses( $(\mathrm{P})$

"I feel that learning becomes easy when using this LSR interactive application. If I combined the syllables wrongly, there would be a warning sound to signal that my answer was incorrect. It helped me by giving me a sign that I have to check my spelling”. (P1)

"Ermmm..easy to understand when using the LSR interactive application compared to the textbook. I can hear the syllable sounds very clearly. The interactive quiz was fun and enabled me to remember easily because the pictures were clear and colorful. The pictures helped me to read the syllables correctly. The interactive quiz helped me to get the correct answers". (P4)

"Using the LSR interactive application was fun. It helped me revise what I could not understand. The quiz made me interested to learn more. The part I like most was identifying the syllables because the voice sound told me the right syllables to match the pictures on the screen". (P5)

"I like answering the quiz. I could know whether I was right or wrong through the responses such as if my answer was right, there would be the sound of hands clapping. When I answered incorrectly, there would also be a sound telling me to try again. The one thing I like about LSR is I can revise and redo my answer if I answered incorrectly and I can try and try until I get the correct answer". (P7)

"At first I was not good in using the computer. But, the LRS application helped me understand which button to click. After a while, I felt comfortable using the LSR interactive application compared to the textbook. The colorful interface attracted me to learn more. The instructions in the application were also clear. I felt confident to pronounce the syllables because I was free to click on the picture repeatedly and could hear the sounds of the syllables being pronounced correctly." (P9)

Theme 3: Suggestion to increase 3 Dimension (3D) words and add Interface and animated pictures.

There were also features that required improvement in the LSR interactive application from the perspective of the teachers and pupils. In their views, the number of 3D words and animation could be increased. In addition, there was a need to introduce the sounds of the syllables before combining the syllables to form the words. All the students interviewed said they liked LSR because of the animation, audio, color and interface elements that attracted their interest in learning. All students suggested putting more words and 3D graphics.

Teachers' Responses (T)

"In my view, it would be good to add a section where pupils can hear the syllable sound first. Then continue to pronounce the syllable to form the word. Maybe the pupils will feel even easier to read the words because they already know which syllable sounds to combine. It would also be good to add $3 D$ animations or moving pictures as well." (T1)

"I think adding number of words and moving pictures like $3 D$ animations should be more interesting. It is usually difficult to maintain the slow learners' attention span. But if there is a stimulus that catches their interest and attention, it will be easy for us to make them stay focused. Other than that I think this application is good. This application can greatly enhance the reading skills of these slow learners." (T2)

Pupils' responses (P)

"Ermmm ...this application is simply awesome. But if teacher can add more animation, it would be better. Feels like watching cartoons." (P1)

"I like it, teacher. But it ended fast. Can teacher add more? It will surely be very interesting. ” (P3)

"I like it to have more real pictures. Maybe teacher can add animal sounds because I like to hear how the animals sound like. I like learning using this application." (P6)

"It is good, teacher. But I hope teacher can add one 
part where I can hear all the syllables first. Then I can identify the syllables easily. That way I can easily put together the correct syllable to match the picture." (P7)

"I think the application is good already, teacher. I enjoy using this application. But if teacher wants to add anything, I hope teacher can change all the pictures to 3D. I think it will be more interesting" (P10)

\section{Discussion}

Based on the data analysis, it can be concluded that this LSR interactive application can assist pupils in pronouncing $\mathrm{CV}+\mathrm{CVC}$ words. Through the interview data, this application also helped facilitate teacher teaching process. The finding of this study is in line with the study conducted by [10], who stated through the observation findings, the use of audio and visual teaching aids has many advantages in the students' learning process From his study findings, $18 \%$ of the survey respondents agreed that using audio visual teaching aids can stimulate students' interests in learning, while $13 \%$ of survey respondents agreed that learning process using audio and visual elements can help students understand teachers' teaching contents. In addition, $10 \%$ of the survey respondents agreed that the learning process using visual audio media can help improve listening ability and helped maintain their focus on the learning process. Finally, $42 \%$ of respondents said that the use of audio and visual media in their learning greatly benefited students' learning process in many ways. The findings of this study are also supported by [23] that interactive application development is necessary to focus on development of students' skills such as reading skills. This finding is also in line with [24] stated that student learning with multimedia application performed better than the group learning using printed module.

The use of LSR interactive application also affected students' confidence and motivation to learn. This is in line with [25] where language learner autonomy can influence students' motivation. Through the analysis of teachers' interview data, it can be concluded that in addition to helping students with $\mathrm{CV}+\mathrm{CVC}$ word reading skills, students also responded positively by helping their peers pronounce the words and also showed no boredom during the learning session using the LSR interactive application. This is in line with the study findings of [7] in 'The Joy of Reading "- An Intervention Program to Increase Reading Motivation for Pupils with Learning Disabilities which showed that using innovative tool had a significant effect in assisting students with cognitive problems in mastering their reading skills. In addition, active learning activities using this innovative tool in 'The Joy of Reading' created a positive learning experience involving mastery of language literacy through a variety of interesting learning activities such as reading reports, role play and sharing of ideas based on reading materials read.

\section{Conclusions}

Teachers who teach in the 21st century need to be more competent and prepared for the challenges in today's educational world. The effectiveness of teaching depends on the continuous efforts of the teachers and all involved. The use of interactive tools in the teaching and learning process is one of the most effective and engaging teaching mediums. A fun learning environment will enable students to enjoy learning. The use of interactive tools can also stimulate students' communication to respond in the classroom. Through its implementation in this study, it can be said that there is an effective use of LSR interactive tool in helping students to read fluently.

\section{REFERENCES}

[1] U.S. Department of Education (2002). No Child Left Behind: A desktop reference, Washington, D. C.: U.S. Department of Education office of Elementary and Secondary Education, 2002.

[2] Akta Pendidikan 1996, Peraturan-Peraturan Pendidikan (Pendidikan Khas) 2013, Putrajaya: Kementerian Pendidikan Malaysia, 2013.

[3] S. Mcleod, K. Crowe, J. McCormack, P. White, Y. Wren, E. Baker, S. Masso, \& S. E. Roulstone, Preschool children's communication, motor and social development: Parents' and educators' concerns, International Journal of Speech-Language Pathology, vol. 20(4), pp. 468-482, 2018.

[4] M. Nislin, N. Sajaniemi, E. Suhonen, M. Sims, R. Hotulainen, S. Hyttinen, \& A. Hirvonen, Demonstration Technique to Improve Vocabulary and Grammar Element in Teaching Speaking at EFL Learners, English Language Teaching, vol. 11(2), pp. 26-30, 2015.

[5] J. Jinxiu, \& Z. Zhengping, Principles and Implementation of Reading Activities in Primary School English Class, English Language Teaching, vol. 9(12), pp. 74- 78, 2016.

[6] R. O. Adebisi, N. A. Liman, \& P. K. Longpoe, Using Assistive Technology in Teaching Children with Learning Disabilities in the 21st Century, Journal of Education and Practice, vol. 6(24), pp. 14-20, 2015.

[7] E. Tovli, "The Joy of Reading" - An Intervention Program to Increase Reading Motivation for Pupils with Learning Disabilities, Journal of Education and Training Studies, vol. 2(4), pp. 69-84, 2014.

[8] E. S. Åberg, Y. Ståhle, I. Engdahl, \& H. Knutes-Nyqvist, Designing a Website to Support Students' Academic Writing Process, Turkish Online Journal of Educational Technology - TOJET, vol. 15(1), pp. 33-42, 2016. 
https://files.eric.ed.gov/fulltext/EJ1086226.pdf

[9] S. Deb, Suraksha, \& P. Bhattacharya, Blended Interaction For Augmented Learning-An Assistive Tool For Cognitive Disability, 12th International Conference on Cognition and Exploratory Learning in Digital Age, vol. 43(2), pp. 155-162, 2018.

[10] K. O. Friday, Primary School Pupils' Response to Audio-Visual Learning Process in Port Harcourt, Journal of Education and Practice, vol. 6(10), pp. 118-123, 2015. https://eric.ed.gov/?id=EJ1081684

[11] R. E. Mayer, \& R. Moreno, Nine Ways to Reduce Cognitive Load in Multimedia Learning, Educational Psychologist, vol. 38, pp. 43-52, 2003. https://doi.org/10.12 07/S15326985EP3801_6

[12] Ministry of Education Malaysia, Malaysia Education Blueprint 2013-2025 (Preschool to Post-Secondary Education), Putrajaya: Kementerian Pendidikan Malaysia, 2013.

[13] U. Yadav, \& R. Mehta, Effectiveness of education intervention programme on life support measures for the nurses working in emergency unit of BPKIHS: a pre-experimental study, Journal of BP Koirala Institute of Health Sciences, vol. 1(1), pp. 14-19, 2018.

[14] R. Kumar, Research Methodology: A Step-by-Step Guide for Beginners (5th edition), London: SAGE Publication Ltd., 2019.

[15] N. Asiamah, H. K. Mensah, \& E. Oteng-Abayie, General, Target, and Accessible Population: Demystifying the Concepts for Effective Sampling, The Qualitative Report, vol. 22(6), pp. 1607-1621, 2017.

[16] L. W. Anderson, \& D. R. Krathwohl, A taxonomy for learning, teaching, and assessing, Abridged Edition, Boston: Allyn and Bacon, 2001.

[17] A. Vello \& A. Raman, Kaedah Analisis \& Interpretasi Data, Sintok, Kedah: UUM Press, 2013.

[18] M. Husnu, Demonstration Technique to Improve Vocabulary and Grammar Element in Teaching Speaking at EFL Learners, English Language Teaching, vol. 11(2), pp. 26-30, 2018. https://files.eric.ed.gov/fulltext/EJ1166126.pdf

[19] C. Graue, Qualitative Research with A Focus On
Qualitative Data Analysis, International Journal of Sales, Retailing and Marketing, vol. 4(9), pp. 53-67, 2015.

[20] M. T. Siti Uzairiah, Kajian Kualitatif dan Analisis Temu Bual, Kuala Lumpur: Aras Publisher, 2017.

[21] T. Sediyani, H. Yufiarti, \& Eko., Integration of Audio Visual Multimedia for Special Education Pre-Service Teachers' Self Reflections in Developing Teaching Competencies, Journal of Education and Practice, vol. 8 (6), pp. 106-112, 2017.

[22] A. Nurkhin, K. Kardoyo, H. Pramusinto, R. Setiyani, \& R. Widhiastuti, Applying blended problem-based learning to accounting studies in higeher education; Optimizing the utilization of social media for learning, International Journal of Emerging Technologies in Learning (iJET), vol. 15(8), pp. 22-39, 2020.https://doi.org/10.3991/ijet.v15i08.1 2201

[23] Z. Nurbekova, V. Grinshkun, G. Aimicheva, B. Nurbekov, \& K. Tuenbaeva, Project-based learning approach for teaching mobile application development using visualization technology, International Journal of Emerging Technologies in Learning (iJET), vol. 15(8), pp. 130-143, 2020. https://doi.org/10.3991/ijet.v15i08.12335

[24] N. Azid, N. Yusoff, M. Z. Ishak, N. Mohd Ali, The creation of technological interactive Cerdik BM Series 1 as an innovation of pedagogical tool to support Malay Language skills, International Journal of Innovative and Exploring Engineering, vol. 8(12), pp. 33-42, 2019.

[25] Y. Chen, Correlation between self-efficacy and English performance, International Journal of Emerging Technologies in Learning (iJET), vol. 15(8), pp. 223-234, 2020. https://doi.org/10.3991/ijet.v15i08.13697

[26] Makrina Zafiri, Alexandra Konstantinidou, Vassiliki Pliogou (2019). The Application of Differentiated Instruction in Reading and Writing to a Boy with Autism in Early Childhood Education. A Case Study. Universal Journal of Educational Research, 7(12), 2609 - 2626. DOI: 10.13189/ujer.2019.071208.

[27] Vasudevan, A. (2017). Slow learners - Causes, problems and educational programmes. International Journal of Applied Research,3(12), 308-313. Retrieved from http://www.allresearchjournal.com/archives/2017/vol3issue 12/PartE/3-11-79-891.pdf 